Article

\title{
Filtration Behaviour and Fouling Mechanisms of Polysaccharides
}

\section{Sondus Jamal, Sheng Chang * and Hongde Zhou}

School of Engineering, University of Guelph, Guelph, ON N1G 2W1, Canada;

E-Mails: sjamal@uoguelph.ca (S.J.); hzhou@uoguelph.ca (H.Z.)

* Author to whom correspondence should be addressed; E-Mail: schang01@uoguelph.ca;

Tel.: +1-519-824-4120 (ext. 56619); Fax: +1-519-836-0227.

Received: 2 May 2014; in revised form: 24 June 2014 / Accepted: 30 June 2014 /

Published: 8 July 2014

\begin{abstract}
This study investigated filtration behaviors of polysaccharides solutions, both alone and in mixture with proteins, in the short-time constant flux filtration with the focus on factors affecting the transmembrane pressure (TMP) increase rate, the irreversible filtration resistance, and the membrane rejection behavior. The results showed that the TMP increase rates in the short-time constant flux filtration of alginate solutions were significantly affected by the calcium addition, alginate concentration, and flux. Although the addition of calcium resulted in a decrease in the TMP increase rate, it was found that the irreversible fouling developed during the filtration increased with the calcium addition, implying that the double-sided effect of calcium on membrane filtration and that the TMP increase rate observed in the filtration does not always reflect the irreversible membrane fouling development. It was also found that for the filtration of solutions containing mixed alginate and BSA, alginate exerted a dominant effect on the TMP increase rate and the membrane exhibited a reduced rejection to both alginate and BSA molecules compared to that in the filtration of the pure alginate or BSA.
\end{abstract}

Keywords: membrane fouling; soluble microbial product (SMP); MBR; concentration polarization; polysaccharides; alginate 


\section{Introduction}

The applications of membrane bioreactors (MBR) technology in municipal and industrial wastewater treatment have been expanded in recent years. However, membrane fouling still remains a critical factor affecting the capital and operational costs of MBRs. In the case of wastewater treatment, mixed liquor contains flocculated bioactive suspended solids, colloidal and soluble microbial products (SMP) as well as dissolved inorganic substances. Current fouling control strategies such as air scouring and flux regulation are proven to be effective to control cake formation and concentration polarization in MBRs. However, SMPs that are mainly composed of polysaccharides and proteins, are regarded as a major foulant affecting long-term membrane fouling in MBRs under air scouring and controlled flux condition [1-3]. Thus, an examination of the fouling mechanism of polysaccharides and proteins is important for controlling membrane fouling in MBRs.

Alginate has been used as a model polysaccharide to study the filtration behaviour and fouling mechanisms of SMPs in many studies [4-10]. Van den Brink et al. [11] found that calcium addition reduced the TMP increase rate but increased the irreversibility of the fouling. Listiarini et al. [12] suggested that cake formation was the main resistance mechanism in the filtration of alginate solution and reported that the cake layer formed by the alginate exhibited an incompressible behaviour in both the presence and absence of calcium. Nataraj et al. [5] also indicated that the cake filtration model fit the entire range of their ultrafiltration data for alginate solutions at a concentration of $20 \mathrm{ppm}$. In contrast, Katsoufidou et al. [13] reported that the internal pore constriction at the beginning of filtration resulted in a rapid irreversible fouling stage in the filtration of alginate without added calcium, but with calcium, cake formation was dominant throughout the filtration and the fouling reversibility was increased. In a later study, Katsoufidou et al. [8] found that the fouling behaviour of sodium alginate was dominant in the filtration of solution containing sodium alginate (SA) and humic acid (HA) such that the behaviour of HA/SA mixtures was quite similar to that of alginate alone even when SA was present in a small proportion. It was also reported that the membrane exhibited a higher rejection to the HA and SA when they were mixed in the solution [8]. Mo et al. [10] found that the effect of calcium addition on alginate fouling depended on the calcium concentration with a positive effect observed at the concentration above a critical value. Thus, most of the previous studies showed that the addition of calcium reduced the filtration resistance caused by the alginate, but increased its irreversibility in the filtration with intermittent permeation [11], or with backwashing [8], or during a relatively long filtration period $[12,13]$.

In this study, the focus is on the filtration behavior of alginate solution in the short-time constant flux filtration mode. The duration of the short-time filtration can be arbitrarily defined between $15 \mathrm{~min}$ and one hour. In this study, a one-hour filtration duration was used. The interest in the short-time filtration mode are because this filtration mode has been widely used in the critical flux and sludge filterability tests. In these tests, the TMP increase rate has been used as the main criteria or indicator to determine the operation flux, sludge filterability, and the fouling potential of solutions $[14,15]$. The aim of this paper is to analyze the typical TMP-time profiles observed in the short-time constant flux filtration of alginate solutions, and examine the effects of calcium addition, change of flux, and the presence of protein on the TMP increased rate and the irreversible fouling development. Another parameter under investigation is the membrane rejection behavior to the protein and polysaccharides in 
the short-time constant flux filtration. The results presented in this paper can develop improved understanding of the factors affecting polysaccharide fouling and the membrane methods to assess the membrane-fouling propensity of polysaccharides.

\section{Materials and Methods}

The single fiber experimental set-up shown in Figure 1 was used for the filtration experiments. The filtration system consisted of a feed tank (1), a single hollow fiber module (2), a pressure transducer with a pressure range -14.5 to 15 psi (Cole Parmer, 68075-32) (3), a peristaltic pump (Minipuls 3, Gilson) (4), a balance (CPA6235, Sartorius) for the permeate flow measurement (5), and a computer data logging system (6). The single hollow fiber membrane module used was made from PVDF hollow fibres with a membrane pore size around $0.04 \mu \mathrm{m}$ (GE Water Process Technologies, Canada). The fiber length was $22 \mathrm{~cm}$ with a $0.9 \mathrm{~mm}$ ID and $1.8 \mathrm{~mm} \mathrm{OD}$, providing a total filtration area of $14 \mathrm{~cm}^{2}$. The filtration experiments were carried out in constant flux mode. Fresh hollow fiber membranes were used for each filtration test and the membrane resistance was determined by clean water filtration. The irreversible membrane fouling $\left(\Delta \mathrm{R}_{\mathrm{m}} \%\right)$ developed during the filtration was assessed by comparing the membrane resistance before and after the filtration.

Figure 1. Schematic of the experimental setup.

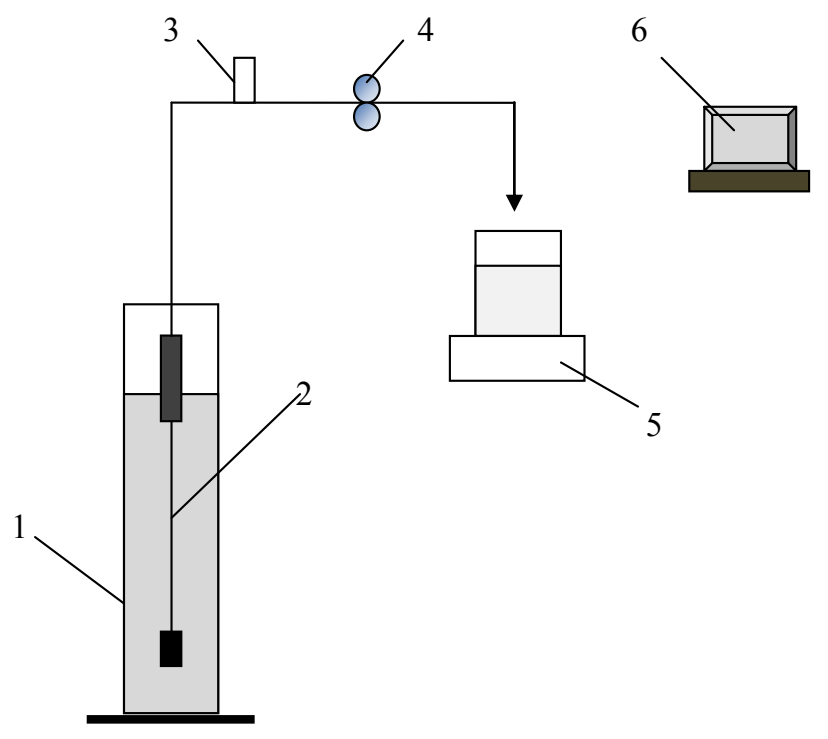

The chemicals used in this study, including sodium alginate (SA), bovine serum albumin (BSA), sodium bicarbonate $\left(\mathrm{NaHCO}_{3}\right)$, and calcium chloride $\left(\mathrm{CaCl}_{2}\right)$, were produced by Acros Organics (Fisher Scientific). A $10 \mathrm{~g} / \mathrm{L}$ alginate solution was made by dissolving the alginate into deionised water with mechanical stirring for around $3 \mathrm{~h}$ to ensure the fully dissolution of the alginate. It was then stored in the refrigerator as the stock solution that was diluted to $1 \mathrm{~g} / \mathrm{L}$ for the zeta potential measurement and to the desired concentration for the filtration experiments $(10$ and $20 \mathrm{mg} / \mathrm{L})$. Sodium bicarbonate of $2 \mathrm{mM}$ was used as a buffer of the alginate solutions used in the filtration. $\mathrm{CaCl}_{2}$ was used to adjust the $\mathrm{Ca}^{2+}$ concentration of $0,6.25,12.5,18.75,25,50,100,222.5 \mathrm{mg} / \mathrm{L}$ for testing effect of calcium on alginate filtration behavior. For the protein mixture experiments, a $5 \mathrm{~g} / \mathrm{L}$ BSA stock solution was made 
by dissolving the BSA into deionised water and then stored in the refrigerator, and used for making the BSA solutions of different concentrations $(0,2.5,5,10,20 \mathrm{mg} / \mathrm{L})$.

The zeta potential of the alginate was measured using a Zetasizer Nano Z instrument (Malvern). Spectrophotometric and colorimetric methods have been used for protein and carbohydrate analysis [16,17]. The protein rejection analysis was carried out using a modified BCA protein assay method for lower concentration samples. The Pierce BCA test kit (cat. No.: 23225, 23227) was used and the Enhanced Protocol was followed with BSA as a standard. The coverage range for the protein calibration curve was $0-250 \mathrm{ppm}$ with 8 measured calibration points. The alginate rejection was carried out in accordance with a modified version of the method of Dubois et al. [16] for lower concentration samples with glucose solution used as a standard. The coverage range of the carbohydrate calibration curve was $0-70 \mathrm{ppm}$ with 8 measured points. The HACH DR 4000 spectrophotometer was used for the absorbance measurement at $562 \mathrm{~nm}$ for protein and at $490 \mathrm{~nm}$ for carbohydrate.

\section{Results and Discussion}

\subsection{Zeta Potential of Alginate Molecules}

Zeta potential reflects the charge density of colloids, which dominates the inter-molecular interactions through long-range repulsive forces. It is thus usually used to assess the aggregation potential of colloids and particulates in water and wastewater. For the membrane filtration, measurement of zeta potential will aid in prediction of long-term colloidal stability of the macromolecules in the concentration polarization $(\mathrm{CP})$ layer formed on the membrane surface.

Figure 2. Box plot for change in Zeta potential $(\mathrm{mV})$ with calcium concentration $(\mathrm{mg} / \mathrm{L})$ in $1 \mathrm{~g} / \mathrm{L} \mathrm{SA}$ and $2 \mathrm{mM} \mathrm{NaHCO} 3$ buffer.

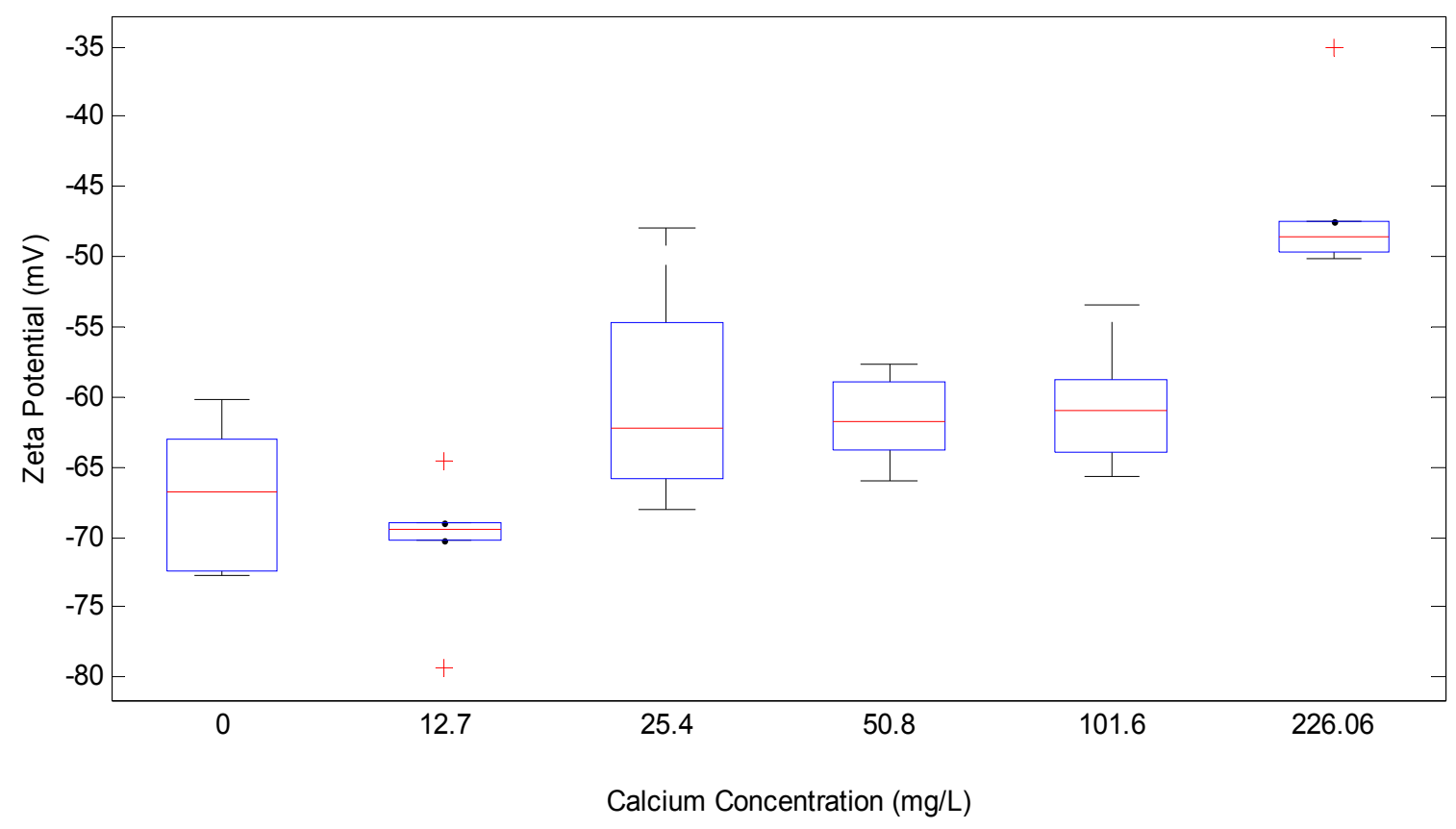


Figure 2 is the box plot for the effect of calcium concentration on the zeta potential of the alginate tested. The measurement showed that the zeta potential of the tested alginate was reduced from $-70.3 \mathrm{mV}$ to $-46 \mathrm{mV}$ when $\mathrm{Ca}^{2+}$ concentration added increased from 0 to $222.5 \mathrm{mg} / \mathrm{L}$. Significant gelling was observed when further increasing the calcium concentration beyond this range.

The zeta potential reduction caused by calcium addition could be attributed to the aggregation of alginate molecules. It is well known that $\mathrm{Ca}^{2+}$ can selectively bond to guluronic acid (G) residues of alginate to form a crosslink between alginate molecules, which can result in the formation of gel aggregates or lumps in a dilute alginate solution [18,19]. Thus, calcium addition can affect the filtration behavior of the alginate through changing the molecular configurations, size, and surface charge of alginate molecules.

\subsection{Short-Time Filtration Behavior of Alginate}

Figure 3 shows the TMP-time profiles obtained in the filtration of $10 \mathrm{mg} / \mathrm{L}$ alginate solutions with different calcium concentrations at a flux of $40 \mathrm{~L} / \mathrm{m}^{2} / \mathrm{h}(\mathrm{LMH})$. From this figure, it can be seen that the TMP profiles for the filtration of alginate solutions under constant flux condition can be characterized by a non-linear initial TMP rise followed by a linear TMP increase. Such a profile was observed in the filtration experiments with alginate solutions of different solution chemistry and concentrations. In fact, such a non-linear/linear TMP profile has also been a typical TMP profile observed in the critical flux tests with mixed liquor in MBRs [15,20]. A general practice in the critical flux and sludge filterability test is to characterize the sludge fouling propensity and filterability based on the linear TMP increase rate.

Figure 3. TMP profiles for experiments with $10 \mathrm{mg} / \mathrm{L} \mathrm{SA}$ and $2 \mathrm{mM} \mathrm{NaHCO}_{3}$ at flux $40 \mathrm{LMH}$.

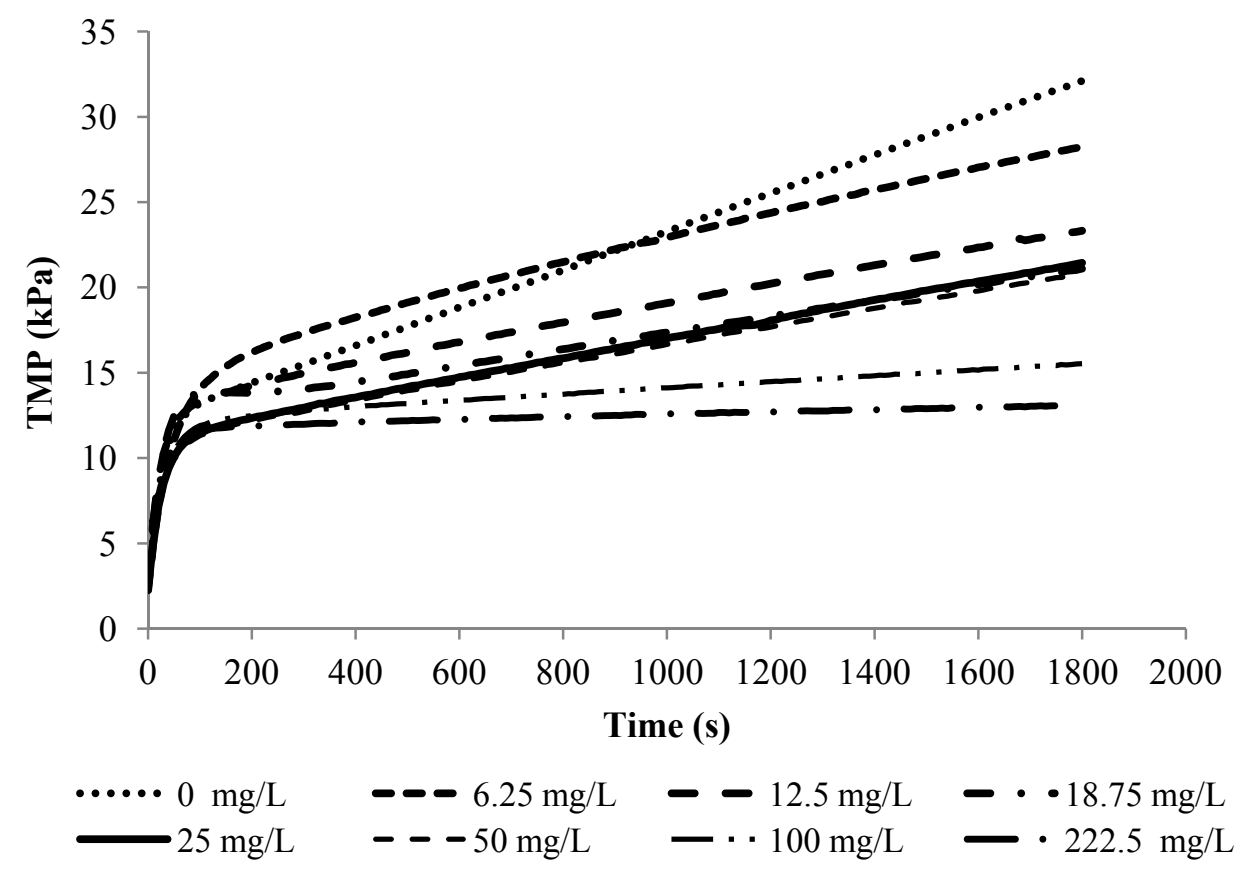




\subsubsection{Factors Affecting the Linear TMP Increase Rate}

The linear TMP increase rate depends on the resistance and the growth rate of the CP layer. The experiments conducted in this study showed that the linear TMP increase rate of alginate solution could be affected by calcium addition, flux, and the presence of protein.

Effect of Calcium Addition: Figure 4 shows the effect of calcium addition on the linear TMP increase rate in the filtration of 10 and $20 \mathrm{mg} / \mathrm{L}$ alginate solutions. The experiments showed that the TMP linear increase rate decreased with increase in the calcium concentration. The effect of the calcium addition was more pronounced at the low calcium concentration range for both 10 and $20 \mathrm{mg} / \mathrm{L}$ alginate solution. As discussed, calcium addition can result in the formation of alginate gel aggregates and reduction in molecular surface charge. The later will reduce the repulsive force between the molecules, which can lead to a more tightly packed CP layer. Thus, the reduced TMP increase rate with the calcium addition should be attributed to the formation of gel aggregates, which will increase the size of alginate, resulting in a reduced resistance of the CP layer.

Figure 4. Effect of calcium addition on TMP increase rate at different SA concentrations (flux $40 \mathrm{LMH} ; 2 \mathrm{mM} \mathrm{NaHCO}$ solution).

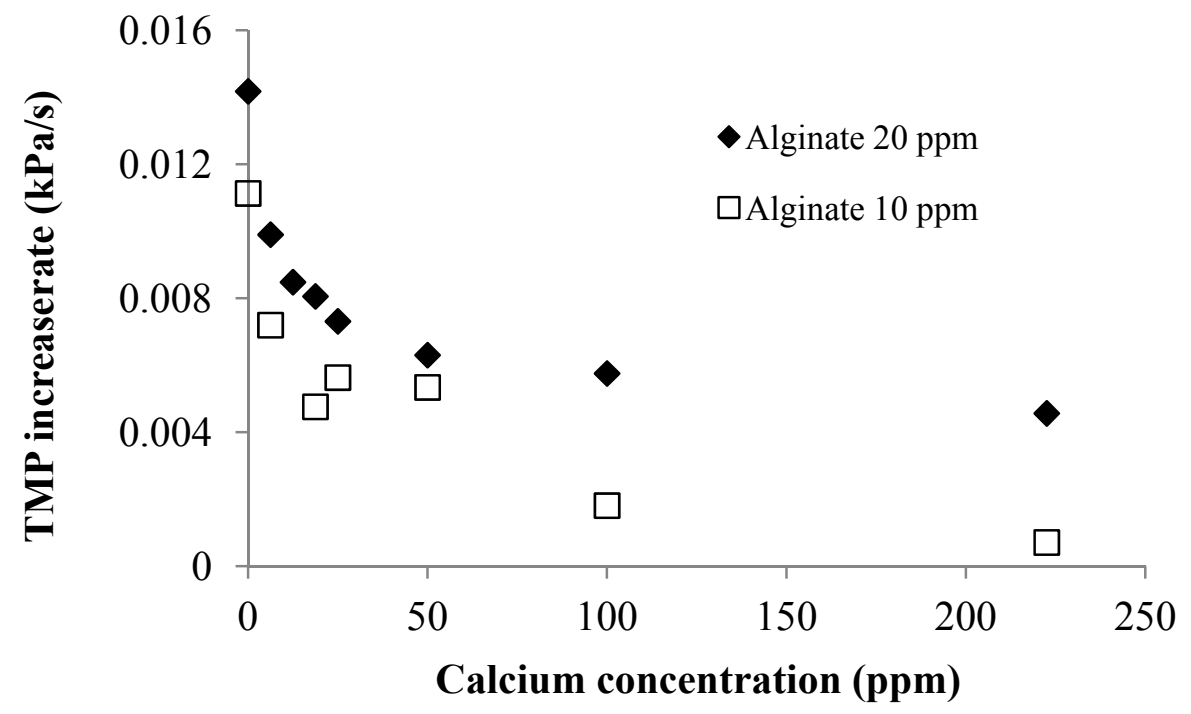

Effect of Operation Flux: Figure 5 shows the effect of the operation flux on the TMP increase rate. It is evident that the linear TMP increase rate increases with the flux. Fitting the experimentally determined TMP increase rate-flux relations with power function trend lines showed that the $\mathrm{dTMP} / \mathrm{d} t$ obtained in the filtration of alginate solutions with different calcium concentrations can be affected by the flux to different indexes, indicating that the properties of the CP layers varies with the concentration of added calcium (Figure 5). 
Figure 5. Effect of flux on TMP rate for filtration with different calcium concentrations (calcium concentrations: $0 \mathrm{ppm}, 6.25 \mathrm{ppm}, 18.5 \mathrm{ppm}$ and $100 \mathrm{ppm}$ ) at $10 \mathrm{ppm}$ sodium alginate concentration and $2 \mathrm{mM}$ sodium bicarbonate concentration.

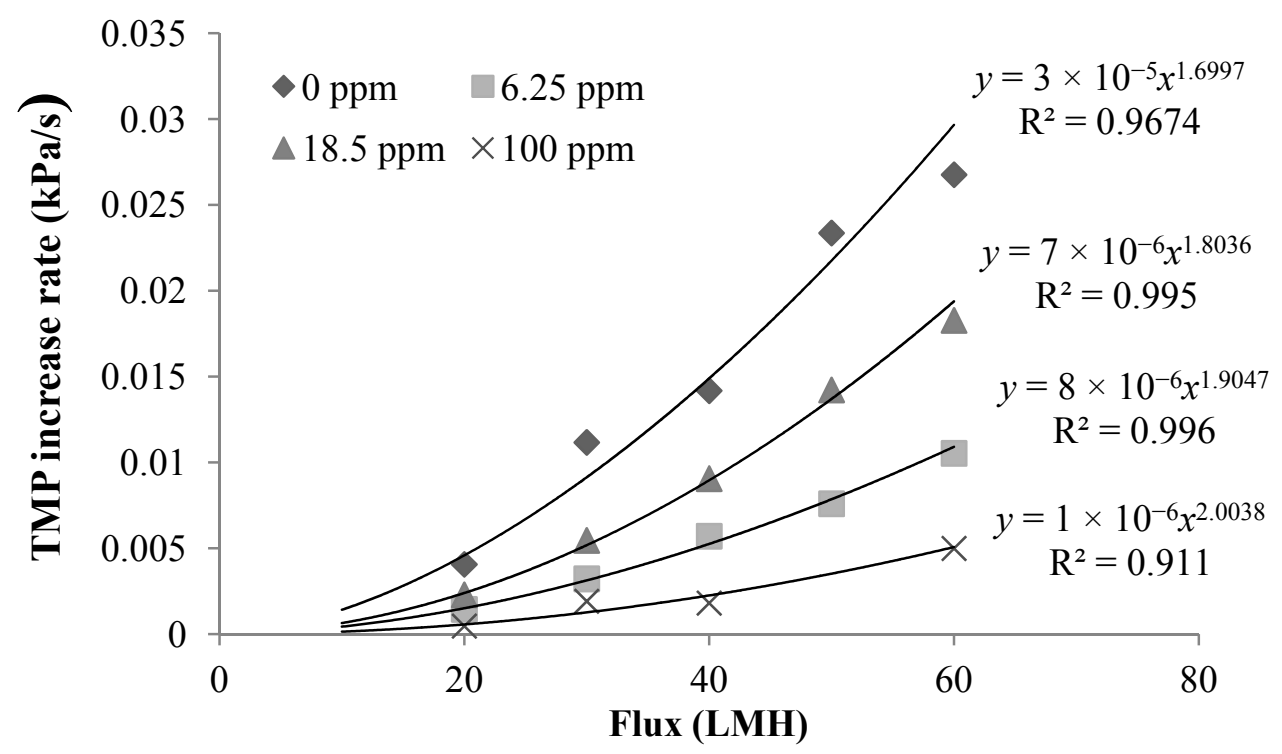

Assuming that the linear TMP increase rate is caused by the growth of CP layer at a constant concentration, the linear TMP increase rate under the constant flux filtration condition can be linked to the specific resistance of CP layer by [21]:

$$
\frac{\mathrm{dTMP}}{\mathrm{d} t}=\eta J^{2} \alpha_{\mathrm{L}} \frac{\varphi_{\mathrm{b}}}{\varphi_{\mathrm{C}}}
$$

where $\eta$ is the water viscosity; $\mathrm{J}$ is the flux; $\alpha_{\mathrm{L}}$ is the thickness-based specific resistance; $\phi_{\mathrm{b}}$ is the solid volume fraction of the bulk solution; and $\phi_{\mathrm{C}}$ is the solid fraction in the CP layer.

Then, the ratio of the specific resistance to the solid volume fraction of the CP layer can be expressed as:

$$
\frac{\alpha_{\mathrm{L}}}{\varphi_{\mathrm{C}}}=\frac{1}{\eta J^{2} \varphi_{\mathrm{b}}} \frac{\mathrm{dTMP}}{\mathrm{d} t}
$$

The parameter $\alpha_{\mathrm{L}} / \phi_{\mathrm{C}}$ reflects the filtration resistance caused by solids, measured in volume, in the unit volume of CP layer. Based on the experimentally determined flux dTMP/dt relationshp, the index for the $\alpha_{\mathrm{L}} / \phi_{\mathrm{C}}$ can be determined using Equation (2). Table 1 summarized the index of $\mathrm{dTMP} / \mathrm{d} t$ and $\alpha_{\mathrm{L}} / \phi_{\mathrm{C}}$ for the filtration of alginate solutions of different calcium concentrations. A positive index for the $\alpha_{\mathrm{L}} / \phi_{\mathrm{C}}$ indicates a compressible CP layer because the $\alpha_{\mathrm{L}} / \phi_{\mathrm{C}}$ increases with the flux or the hydraulic drag, while the CP layer is incompressible for an index close to zero. From Table 1, it can be seen that the $\mathrm{CP}$ layers for the filtration of alginate solutions with calcium concentration of 18.5 and $100 \mathrm{mg} / \mathrm{L}$ exhibited an index close to zero, indicating an incompressible behavior of the CP layers. However, it is interesting to note that the $\alpha_{\mathrm{L}} / \phi_{\mathrm{C}}$ in the flux range of 20 to $60 \mathrm{LMH}$ showed a negative index in the filtration of the alginate solution without calcium addition and at the calcium concentration $6.25 \mathrm{mg} / \mathrm{L}$. The negative index suggests that the resistance caused by the solids per unit volume of CP concentrate was reduced with increase in the flux. Such a trend is difficult to explain by the 
conventional filtration theory without considering the effect of the molecular properties of alginate. Our recent research revealed that the alginate used in this study had a molecular weight $\left(M_{w}\right)$ of $186 \mathrm{kDa}$ and a Mark-Houwink $\alpha$ parameter of 1.01 by using a size exclusion chromatography (SEC) equipped with the light scattering detectors and the viscometer [22]. The $\alpha$ parameter above 0.8 indicates that the alginate is a semi-flexible polymer with a molecular configuration close to a rodshaped polymers. A reduced $\alpha_{L} / \phi_{C}$ value with the increased flux may suggest that the increased flux resulted in an increased packing randomness or lower packing density of the alginate molecules in the concentration polarization layer. On the other hand, it is known that concentrated alginate solutions can exhibit Non-Newtonian shear-thinning behavior, which results in a reduced viscosity with increase in the shear rate [23]. Thus, the resistance behavior of the concentration formed by alginate under the low flux condition, where the retained alginate has not been fully compressed, may be different from those described by the conventional filtration theory due to the effect of the molecular properties of alginate. Thus, the change in the index of $\alpha_{\mathrm{L}} / \phi_{\mathrm{C}}$ reflects the role of the molecule configuration of polysaccharide molecules in determination of resistance characteristics of CP layer formed in filtration of polysaccharide solution.

Table 1. Flux effect power index for $\mathrm{dTMP} / \mathrm{d} t$ and $\alpha_{\mathrm{L}} / \phi_{\mathrm{C}}$.

\begin{tabular}{ccc}
\hline Calcium Concentration $(\mathbf{m g} / \mathbf{L})$ & $\boldsymbol{a}$ for $\mathbf{d T M P} / \mathbf{d} \boldsymbol{t} \propto \boldsymbol{J}^{\mathbf{a}}$ & $\boldsymbol{b}$ for $\boldsymbol{\alpha}_{\mathbf{L}} / \boldsymbol{\phi}_{\mathbf{C}} \propto \boldsymbol{J}^{\mathbf{b}}$ \\
\hline 0 & 1.70 & -0.3 \\
6.25 & 1.80 & -0.20 \\
18.5 & 1.97 & -0.03 \\
100 & 2.00 & -0.00 \\
\hline
\end{tabular}

Figure 6. Effect of protein addition on TMP rate.

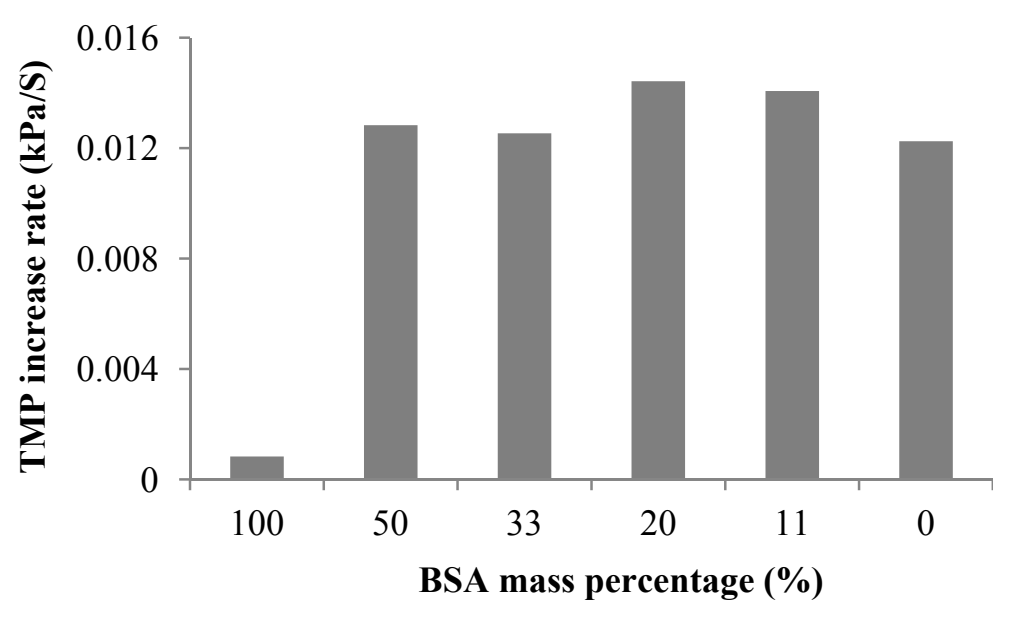

Effect of Protein Presence: The main components of SMPs are protein and polysaccharides. To investigate the effect of protein presence on the filtration behavior of alginate solutions, filtration experiments were conducted using alginate solutions with different BSA concentrations. As shown in Figure 6, the experiments showed that the linear TMP increase rate caused by BSA was significantly lower than that by alginate. For the solution containing the mixture of BSA and alginate, the alginate was found to exert a dominant effect on the linear TMP increase rate, while the effect of BSA on the TMP increase rate in the short-time constant flux filtration was found insignificant. The insignificant 
effect of the BSA presence on the TMP increase rate is understandable given the large difference in the molecular weight and configuration between alginate and BSA molecules, which may suggest that it is the alginate that forms the structure of the CP layer in the filtration of the solution of protein and alginate mixture.

\subsection{Factors Affecting Irreversible Membrane Resistance}

Irreversible fouling is caused by molecules or colloids firmly attached to the membrane surface and pores, which results in the changes in membrane permeability. In this study, irreversible resistance is characterized by comparing the membrane resistance before and after the filtration by using clean water filtration testing. Figure 7 shows the membrane resistance change after 60 min filtration of alginate solutions of different calcium concentrations at flux $40 \mathrm{LMH}$. The experiments showed that the addition of calcium exerted an evident effect on the irreversible fouling development in the filtration of the $20 \mathrm{ppm}$ alginate solutions, where the irreversible resistance increased with calcium concentration at the low calcium concentration range but leveled off at the relatively high calcium concentration. However, it was noticed that the effect of calcium on the irreversible resistance was less profound with the $10 \mathrm{ppm}$ alginate solutions, although a negative effect of calcium on the irreversible resistance was also observed. The effect of the calcium on the irreversible resistance in the low calcium concentration range $(6.25-25 \mathrm{mg} / \mathrm{L})$ indicates the role of $\mathrm{Ca}^{2+}$ in affecting the membrane-alginate interactions. The calcium ions increased the attachment of the alginate molecules on the membrane surface through reducing the negative charge of the alginate molecules and/or forming positive charged contact points along the alginate molecular chains that will "fasten" the alginate molecules on the negatively charged membrane surface. However, the increase in the calcium concentration could result in the formation of alginate aggregates which can form a more reversible cake layer, probably due to the largely reduced specific contact surface area with the large aggregates formed under high calcium concentration.

Figure 7. Effect of calcium addition on irreversible resistance (flux $40 \mathrm{LMH} ; 2 \mathrm{mM}$ $\mathrm{NaHCO}_{3}$ solution).

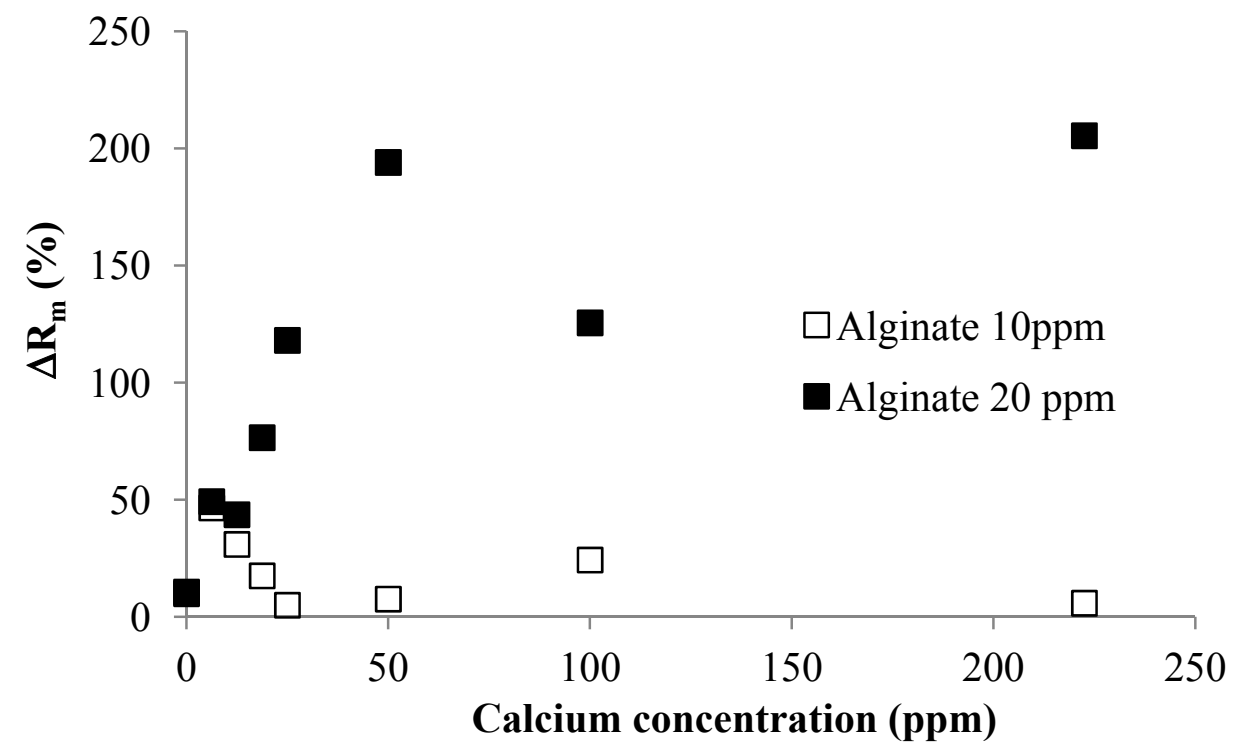


Figure 8 shows the effect of the flux on the irreversible resistance in the flux range 40 to $60 \mathrm{LMH}$ for the short-time constant flux filtration of the alginate solution with and without calcium addition. In these experiments, the total filtrate volume was maintained the same by adjusting the filtration time. As expected, the increased flux resulted in more serious membrane fouling for the same solution condition.

Figure 8. Effect of operational flux on irreversible resistance.

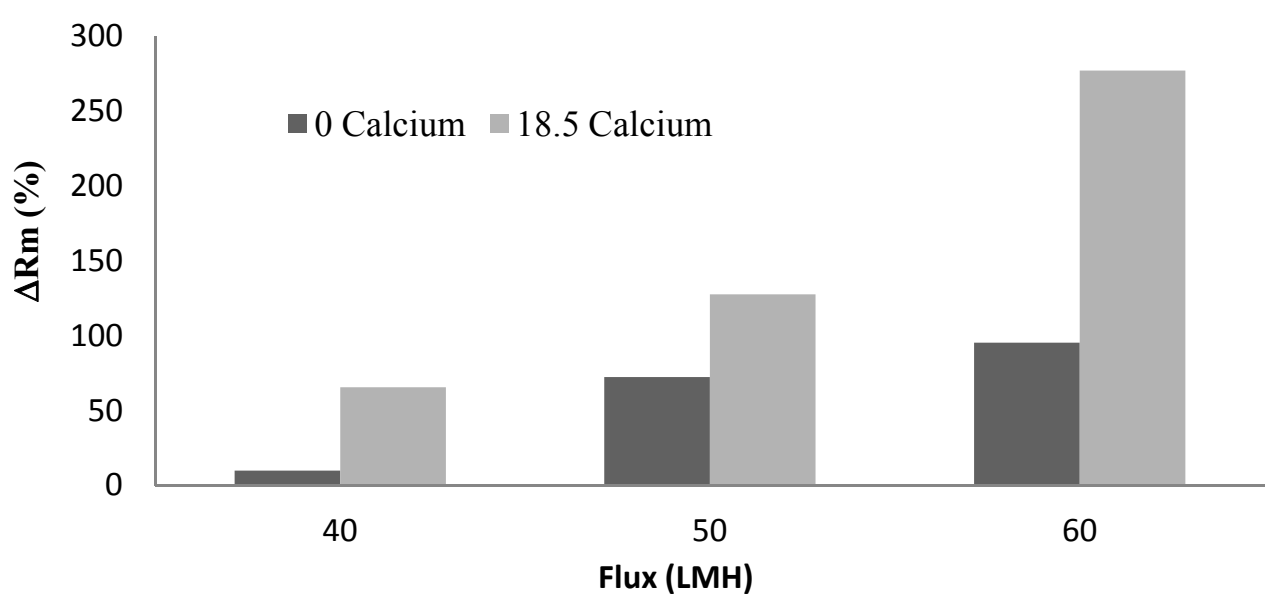

Figure 9 shows the effect of protein addition on the irreversible resistance. It was found that the addition of protein significantly increased the development of the irreversible resistance although both pure BSA and alginate solution caused insignificant irreversible fouling after 60 min filtration. The experiments also showed that the mass ratio of BSA to alginate affecting the irreversible fouling development with the highest irreversible fouling observed in the filtration of solution with a BSA to alginate ratio around $33 \%$.

Figure 9. Effect of protein addition on irreversible resistance.

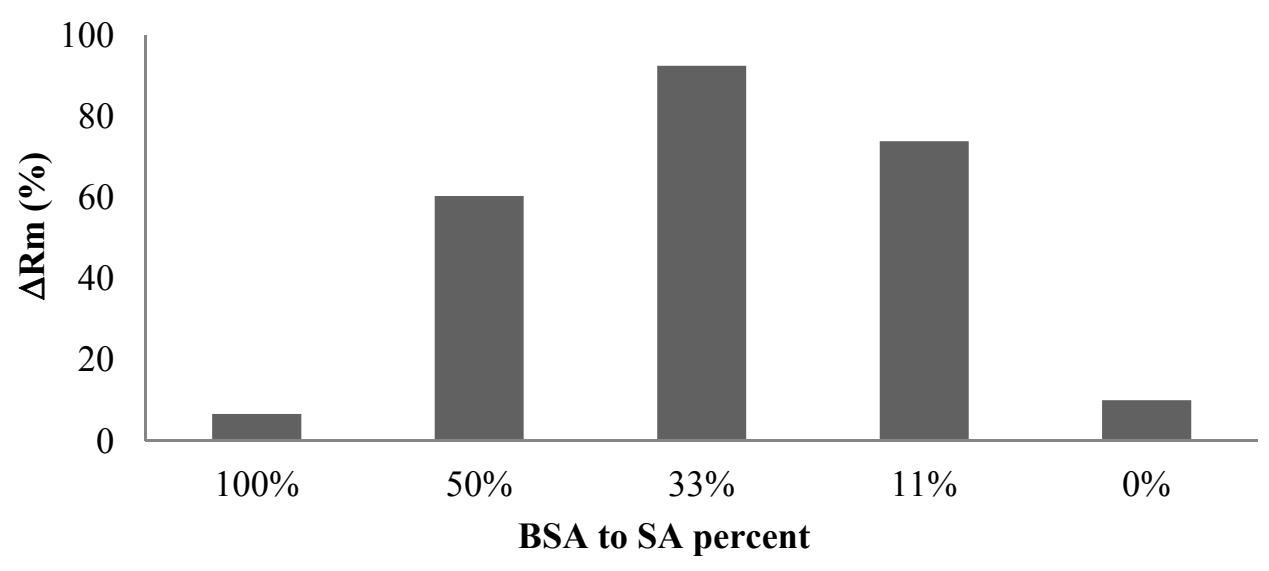

Irreversible fouling is a key factor affecting the long-term stable operation of membrane filtration. Thus, determining the irreversible fouling potential of mixed liquor or other filtration solutions is of critical importance for the membrane filtration operation and design. Although the TMP increase rate is commonly used as a fouling potential indicator, this study shows that the TMP increased rate observed in the short constant flux filtration may not be a reliable indicator to predict the membrane 
fouling behavior of polysaccharide. Figure 10 shows the irreversible resistance developed during the filtration against the corresponding TMP increase rate, which shows that there is no direct relationship between the TMP increase rate and the irreversible fouling development, which suggested that it is necessary to measure both the TMP increase rate and the membrane resistance before and after the filtration to determine the fouling potential of the filtration solutions.

Figure 10. Relationship between irreversible resistances and TMP rate $(\mathrm{kPa} / \mathrm{s})$.

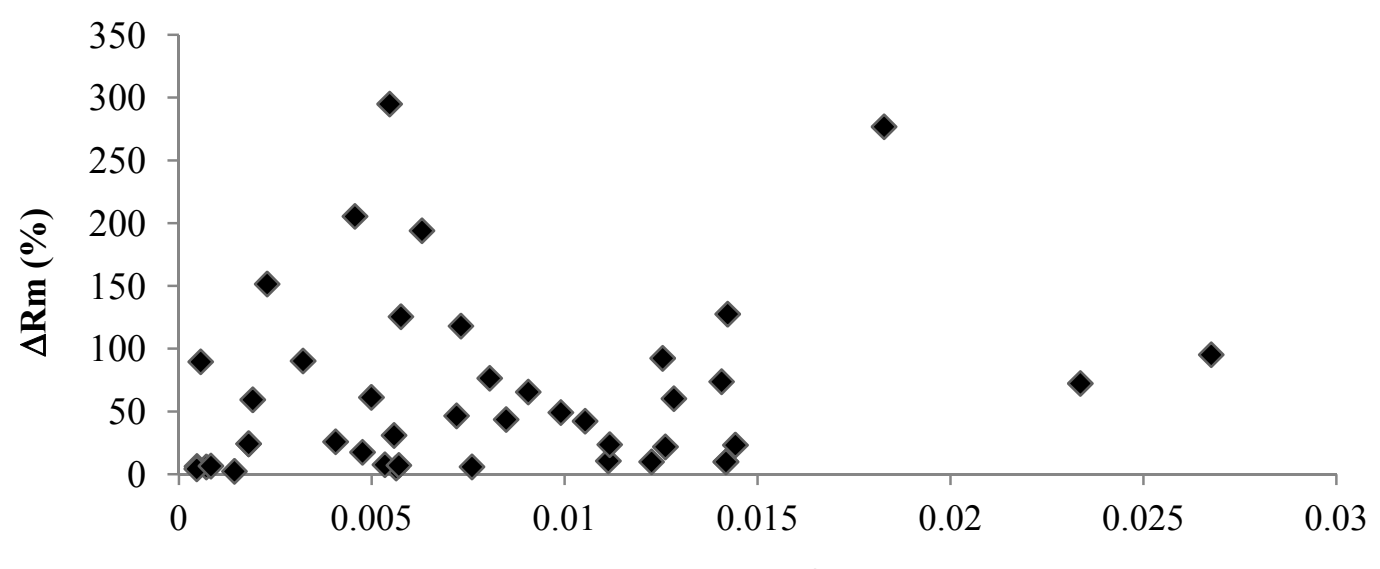

TMP Rate (kPa/s)

\subsection{Membrane Rejection to Alginate and BSA}

The membrane rejection behavior to alginate and BSA was assessed by conducting filtration experiments with solutions of different alginate/BSA compositions, including solutions with alginate $(\mathrm{mg} / \mathrm{L}) / \mathrm{BSA}(\mathrm{mg} / \mathrm{L})$ ratios of $20 / 0,20 / 10,20 / 20$, and $0 / 20$. Samples were taken in the filtration time periods of 0 to 20,20 to 40 , and 40 to $60 \mathrm{~min}$ for the carbohydrates and protein analysis. Figures 11 and 12 show the alginate and BSA rejection during the different sampling periods for the solutions tested.

Figure 11. Alginate rejection for filtration of solutions with different ratios of BSA to SA.

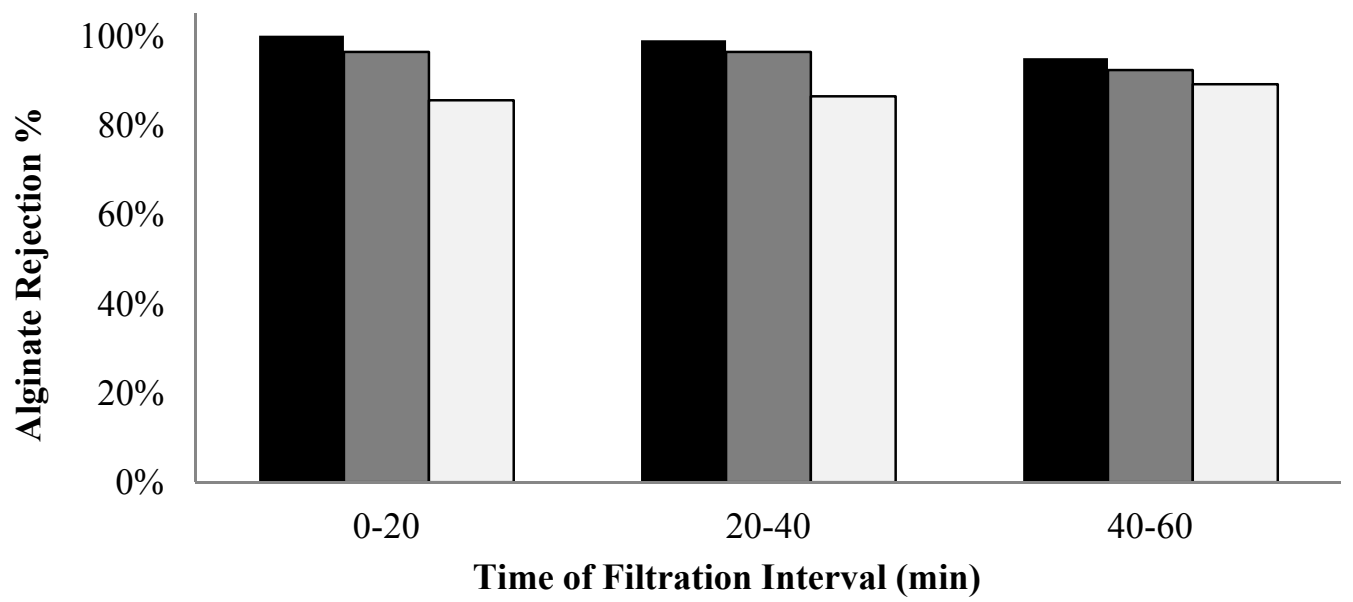

—SA $20 \mathrm{mg} / \mathrm{L} \quad \square \mathrm{SA} 20 \mathrm{mg} / \mathrm{L}$; BSA: $20 \mathrm{mg} / \mathrm{L} \quad$ SA $20 \mathrm{mg} / \mathrm{L}$; BSA $10 \mathrm{mg} / \mathrm{mL}$ 
Figure 12. Protein rejection for filtration of solutions with different ratios of BSA to SA.

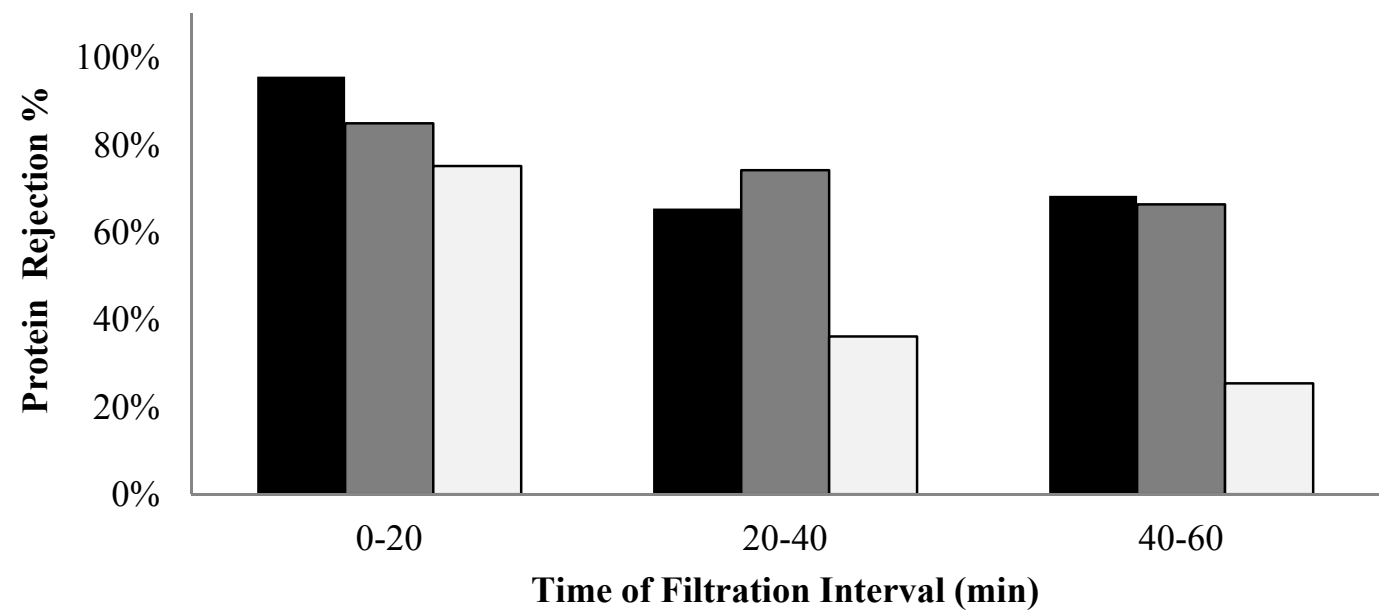

चBSA: $20 \mathrm{mg} / \mathrm{L} \quad \square \mathrm{SA} 20 \mathrm{mg} / \mathrm{L}$; BSA $10 \mathrm{mg} / \mathrm{mL} \quad$ 口SA $20 \mathrm{mg} / \mathrm{L} ; \mathrm{BSA}: 20 \mathrm{mg} / \mathrm{L}$

The membrane exhibited an average $98 \%$ rejection to alginate in the filtration of pure alginate solution and the highest rejection occurred in the 0 to $20 \mathrm{~min}$ period. It is interesting to note that the membrane rejection to alginate was lower for the mixed alginate/BSA solution, particularly for the solution with $20 \mathrm{mg} / \mathrm{L}$ alginate and $10 \mathrm{mg} / \mathrm{L}$ BSA. For the pure BSA solution, the membrane exhibited an average rejection of $76 \%$ over the one-hour filtration period with an evident low rejection in the time periods of 20 to 40 and 40 to $60 \mathrm{~min}$. The presence of the alginate also resulted in a reduction in the protein rejection and the largest reduction occurred with the solution containing $50 \%$ protein and alginate.

The transmission of the alginate or protein molecules from the feed to the permeate side depends on the rejection characteristics of the membrane and the $\mathrm{CP}$ layer. The reduced rejection with the filtration time suggests that the effect of concentration polarization on the observed membrane retention. But it is also worth noting that the experimental results obtained in this study showed that the CP layer formed by the mixture of alginate and BSA exhibited a lower rejection to both alginate and BSA molecules. As the water permeates through the concentration polarization layer, the concentration of the polysaccharides or proteins in the permeate flow can be assumed in equilibrium with that of polysaccharides or proteins in the concentration polarization layer. An increased polysaccharide or protein concentration in the permeate flow (or a reduced membrane rejection) may suggest an increase in the chemical potential of the polysaccharides or protein in the concentration polarization layer, which could result from weakened intermolecular interactions caused by the mixing of the protein and alginate.

\section{Conclusions}

The short-time constant flux filtration mode is widely used in the critical flux test and sludge filterability measurement. This study showed that for the short-time constant flux filtration of alginate solutions, the TMP time profiles can be characterized by a non-linear TMP rise, followed by a linear TMP increase. The linear TMP increase rate can be significantly affected by the presence of calcium ions and the flux condition. For the filtration of the mixed alginate and BSA, the alginate exerted a 
dominant effect on the TMP increase rate. It was found that the irreversible fouling developed through the filtration period increased with the addition of calcium, and that the TMP increase rate exhibited in the short-time constant flux filtration did not always reflect the development of the irreversible fouling during the filtration period. For membrane rejection to the alginate and BSA, it was found that the $\mathrm{CP}$ layers formed by the mixed alginate and BSA exhibited a lower rejection to both alginate and BSA molecules compared to the CP layers formed by pure alginate or BSA molecules.

\section{Acknowledgments}

The authors thank the Canadian Water Network (PRF ITM2-2011) and the Canadian Foundation of Innovation (28061) for their support of this research.

\section{Author Contributions}

Authors are all involved in the research related to the development of this manuscript.

\section{Conflicts of Interest}

The authors declare no conflict of interest.

\section{References}

1. Rosenberger, S.; Laabs, C.; Lesjean, C.; Gnirss, R.; Amy, G.; Jekel, M.; Schrotter, J.C. Impact of colloidal and soluble organic material on membrane performance in membrane bioreactors for municipal wastewater treatment. Water Res. 2006, 40, 710-720.

2. Lyko, S.; Al-Halbouni, D.; Wintgens, T.; Janot, A.; Hollender, J.; Dott, W.; Melin, T. Polymeric compounds in activated sludge supernatant-Characterisation and retention mechanisms at a full-scale municipal membrane bioreactor. Water Res. 2007, 41, 3894-3902.

3. Shen, Y.; Zhao, W.; Xiao, K.; Huang, X. A system insight into fouling propensity of soluble microbial products in membrane bioreactors based on hydrophobic interaction and size exclusion. J. Membr. 2010, 346, 187-193.

4. Kerchove, A.J.d.; Elimelech, M. Formation of polysaccharide gel layers in the presence of $\mathrm{Ca}^{2+}$ and $\mathrm{K}^{+}$ions: Measurements and mechanisms. Biomacromolecules 2007, 8, 113-121.

5. Nataraj, S.; Schomäcker, R.; Kraume, M.; Mishra, I.M.; Drews, A. Analyses of polysaccharide fouling mechanisms during crossflow membrane filtration. J. Membr. Sci. 2008, 308, 152-161.

6. Wang, X.; Waite, T.D. Impact of gel layer formation on colloid retention in membrane filtration processes. J. Membr. Sci. 2008, 325, 486-494.

7. Van de Ven, W.J.C.; Sant, K.V.; Punt, I.G.M.; Zwijnenburg, A.; Kemperman, A.J.B.; van der Meer, W.G.J. Hollow fiber dead-end ultrafiltration: Influence of ionic environment on filtration of alginates. J. Membr. Sci. 2008, 308, 218-229.

8. Katsoufidou, K.S.; Sioutopoulos, D.C.; Yiantsios, S.G.; Karabelas, A.J. UF membrane fouling by mixtures of humic acids and sodium alginate: Fouling mechanisms and reversibility. Desalination 2010, 264, 220-227. 
9. Listiarini, K.; Tan, L.; Sun, D.D.; Leckie, J.O. Systematic study on calcium-alginate interaction in a hybrid coagulation-nanofiltration system. J. Membr. Sci. 2011, 370, 109-115.

10. Mo, Y.; Xiao, K.; Shen, Y.; Huang, X. A new perspective on the effect of complexation between calcium and alginate on fouling during nanofiltration. Sep. Purif. Technol. 2011, 82, 121-127.

11. Van de Brink, P.; Zwijnenburg, A.; Smith, G.; Temmink, H.; van Loosdrecht, M. Effect of free calcium concentration and ionic strength on alginate fouling in cross-flow membrane filtration. J. Membr. Sci. 2009, 345, 207-216.

12. Listiarini, K.; Chun, W.; Sun, D.D.; Leckie, J.O. Fouling mechanism and resistance analyses of systems containing sodium alginate, calcium, alum and their combination in dead-end fouling of nanofiltration membranes. J. Membr. Sci. 2009, 344, 244-251.

13. Katsoufidou, K.S.; Yiantsios, S.G.; Karabelas, A.J. Experimental study of ultrafiltration membrane fouling by sodium alginate and flux recovery by backwashing. J. Membr. Sci. 2007, $300,137-146$.

14. Le Clech, P.; Jefferson, B.; Chang, I.S.; Judd, S.J. Critical flux determination by the flux step method in a submerged membrane bioreactor. J. Membr. Sci. 2003, 227, 81-93.

15. Li, J.; Zhang, X.; Cheng, F.; Liu, Y. New insights into membrane fouling in submerged MBR under sub-critical flux condition. Bioresour. Technol. 2013, 137, 404-408.

16. Dubois, M.; Gilles, K.A.; Hamilton J.K.; Rebers P.A.; Smith, F. Colorimetric method for determination of sugars and related substances. Anal. Chem. 1956, 28, 350-356.

17. Bradford, M.M. A rapid and sensitive method for the quantisation of microgram quantities of protein utilizing the principle of protein-dye binding. Anal. Biochem. 1976, 72, 248-254.

18. Draget, K.O.; Smidsrød, O.; Skjåk-Bræk, G. Alginates from Algae. In Polysaccharides and Polyamides in the Food Industry. Properties, Production, and Patents; Steinbüchel, A., Rhee, S.K., Eds.; WILEY-VCH: Weinheim, Germany, 2005.

19. Grant, G.T.; Morris, E.R.; Rees, D.A.; Smith, P.J.C.; Thom, D. Biological interactions between polysaccharides and divalent cations: The egg-box model. FEBS Lett. 1973, 32, 195-198.

20. Koseoglu, H.; Yigit, N.O.; Iversen, V.; Drews, A.; Kitis, M.; Lesjean, B.; Kraume, M. Effects of several different flux enhancing chemicals on filterability and fouling reduction of membrane bioreactor (MBR) mixed liquors. J. Membr. Sci. 2008, 320, 57-64.

21. Chang, Jamal, S.; Chen, H.; Zhou, H.; Hong, Y.; Adams, N. A novel approach to analyzing concentration polarization of polysaccharide solutions. Water Sci. Technol. 2013, doi:10.2166/wst.2014.038.

22. Jamal, S. Filtration Behavior and Fouling Mechanisms of Polysaccharides. M.Sc. Thesis, The University of Guelph, Guelph, ON, Canada, 2014.

23. Masuelli, M.A.; Illanes, C. Review of the characterization of sodium alginate by intrinsic viscosity measurements. Comparative analysis between conventional and single point methods. Int. J. BioMater. Sci. Eng. 2014, 1, 1-11.

(C) 2014 by the authors; licensee MDPI, Basel, Switzerland. This article is an open access article distributed under the terms and conditions of the Creative Commons Attribution license (http://creativecommons.org/licenses/by/3.0/). 